Reprod. Nutr. Dévelop., 1988, 28 (1), 39-59.

\title{
Rôles et mécanismes d'action de la somatotropine (hormone de croissance) chez le ruminant en lactation
}

\author{
Y. CHILLIARD
}

Laboratoire de la Lactation,

I.N.R.A., Theix, 63122 Ceyrat, France.

\section{Summary. Effects of somatotropin (growth hormone) in lactating ruminants.}

In 18 short-term trials from the literature using dairy cows, somatotropin resulted in increased milk yield $(+4.0 \mathrm{~kg} / \mathrm{d})$, increased fat, lactose and protein secretions, decreased dry matter intake $(-0.5 \mathrm{~kg} / \mathrm{d})$ and decreased calculated energy balance $(-4.2 \mathrm{Mcal} / \mathrm{d})$. Milk composition was also changed (fat, $+1.9 \mathrm{~g} / \mathrm{kg}$; protein, $-1.4 \mathrm{~g} / \mathrm{kg}$, and lactose, + $0.6 \mathrm{~g} / \mathrm{kg}$ ), due to the fact that treated cows were often in negative energy balance. In 15 long term trials, somatotropin resulted in increased milk yield $(+5.7 \mathrm{~kg} / \mathrm{d})$ and increased dry matter intake $(+1.2 \mathrm{~kg} / \mathrm{d})$, whereas calculated energy balance decreased $(-2.2 \mathrm{Mcal} / \mathrm{d})$.

In 4 trials, digestive efficiency did not seem to be altered by somatotropin. In two longterm trials, body lipids (as estimated by deuteriated water space) were about $40 \mathrm{~kg}$ lower in treated cows, probably reflecting a lower lipid deposition, owing to their lowered energy balance.

Current hypothesis on mechanisms of action of somatotropin or somatomedins are discussed, concerning mammary tissue (secretory cell number or metabolic activity), as well as teleophoretic adaptations that alter nutrient partitioning between mammary, liver, muscle and adipose tissues, by way of modifications of tissue responsiveness to homeostatic insulinic or adrenergic regulations. Somatotropin could indirectly stimulate metabolic activity in mammary cells. Simultaneously, it could decrease adipose tissue lipogenesis and increase fatty acid mobilization and oxidation in other tissues, thus allowing decreased glucose and amino acid oxidations that insure adequate nutrient supply to the mammary gland.

La somatrotropine (ou hormone de croissance) est un polypeptide d'origine hypophysaire ayant de multiples effets métaboliques. Outre ses effets stimulants sur la croissance osseuse et l'anabolisme protéique, on connaît depuis plusieurs décennies ses effets galactopoiétiques (augmentation de la production laitière au cours d'une lactation déjà établie).

Au cours de cette revue nous envisagerons successivement :

1) les relations entre la sécrétion de l'hormone endogène et le potentiel laitier des animaux ;

2) les effets d'injections de somatotropine sur les performances laitières, et

3) les mécanismes d'action, parfois encore hypothétiques, qui peuvent expliquer ces effets. 
Le lecteur pourra se reporter aux excellentes revues de Bauman et McCutcheon (1986), Johnsson et Hart (1986), Gluckman et al. (1987) et Peel et Bauman (1987) pour une analyse plus détaillée de l'ensemble des travaux publiés sur ce sujet. Nous nous sommes en particulier efforcé d'envisager les mécanismes d'action de la somatotropine exogène en confrontant les données physiologiques et métaboliques à des récapitulatifs aussi complets que possible des résultats zootechniques obtenus dans les essais à court et à long terme.

\section{Somatotropine endogène et potentiel laitier}

La somatotropine est une des hormones essentielles du complexe galactopoiétique hypophysaire permettant de maintenir une lactation établie chez le ruminant (revue de Forsyth, 1983).

Chez l'animal intact on observe généralement que les teneurs en somatotropine circulante, et probalement sa sécrétion, sont accrues en début de lactation, particulièrement chez les vaches fortes productrices de lait, qui présentent en outre fréquemment une diminution de l'insulinémie. Ces modifications hormonales peuvent être liées au potentiel génétique des animaux ou à leur état physiologique post-partum, mais plus probablement à leur bilan nutritionnel négatif et à leur faible glycémie, puisque leur capacité d'ingestion est insuffisante à ce stade où leurs besoins (le prélèvement des métabolites par la mamelle) sont très élevés (revue de Chilliard, 1987).

II est cependant possible que les races ou les individus à fort potentiel laitier présentent, à bilans nutritionnels comparables, des taux de somatotropine endogène plus élevés, bien que les données existantes soient peu nombreuses et contradictoires (Hart, 1983 ; Land et al., 1983 ; Truscott et al., 1983 ; Flux et al., 1984 ; Barnes et al., 1985 ; Lukes et al., 1987 ; Kazmer et Oyler, 1987).

\section{Effets d'injections de somatotropine sur les performances laitières}

Les premiers essais ont été réalisés en utilisant de l'hormone d'origine hypophysaire, ce qui explique leur faible nombre et leurs courtes durées. La production semi-industrielle de somatotropine bovine en utilisant les techniques de recombinaison génétique a depuis quelques années permis des expérimentations variées, à grande échelle et à long terme, sur les effets de l'hormone exogène injectée quotidiennement (Bauman et al., 1982, 1985), et plus récemment avec des formes " retard " de la somatotropine recombinée.

\section{Essais de courte durée (1 à 3 semaines).}

La plupart des essais ont été réalisés sur vaches de race pie-noire (Frisonne ou Holstein) après le pic de lactation, à partir du $3^{\mathrm{e}}$ mois. Les réponses enregistrées avec des doses injectées comprises entre 25 et 50 unités par jour sont résumées dans le tableau 1. 


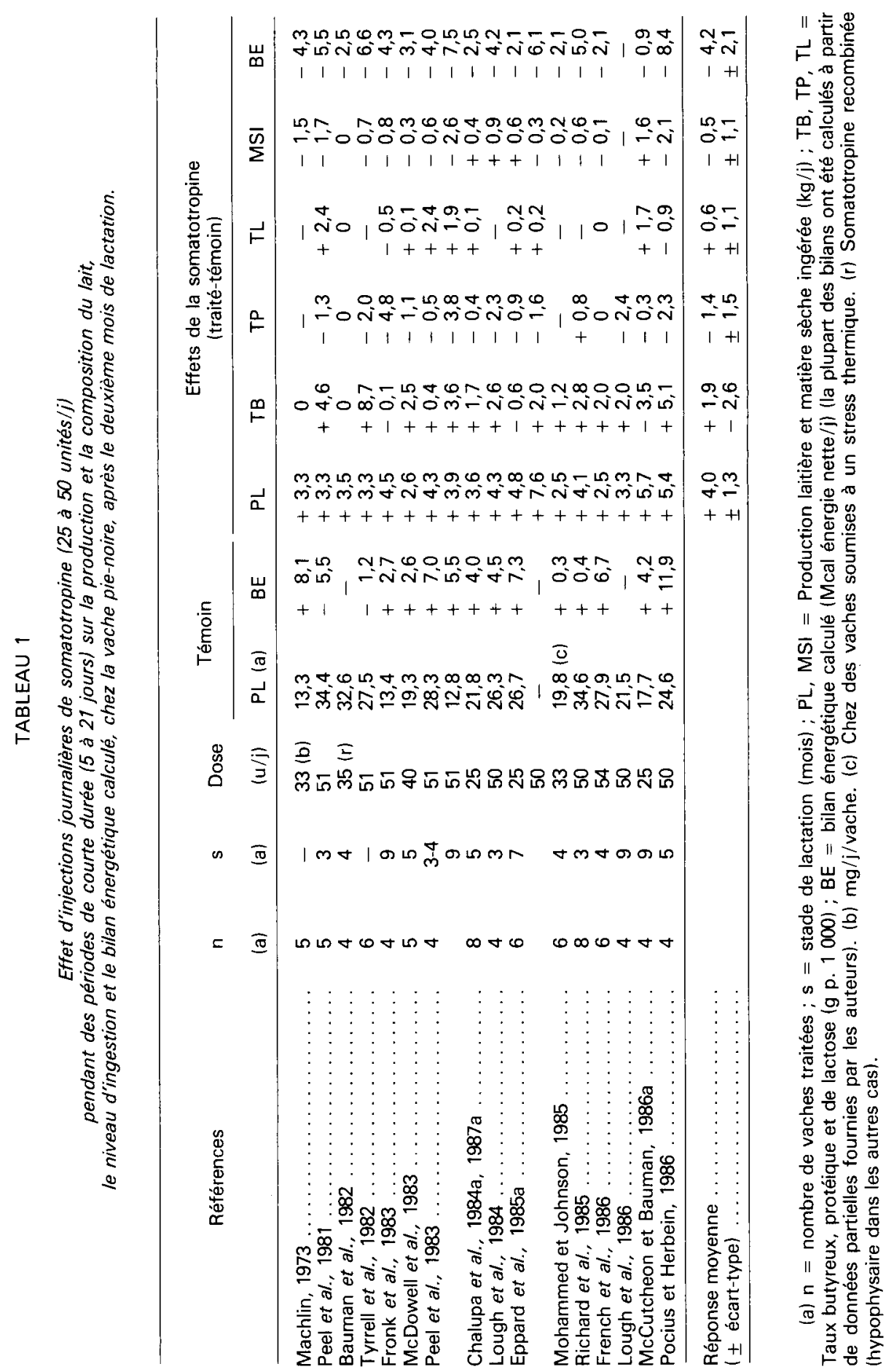


La production laitière augmente très rapidement (en quelques jours) et fortement (de $4 \mathrm{~kg} / \mathrm{j}$ en moyenne dans 18 essais, soit $+17 \%$ ), et dans certains cas la teneur en lactose du lait est accrue $(0,6 \mathrm{~g} / \mathrm{l}$ en moyenne sur les 18 essais). Par contre, l'ingestion de la ration n'augmente presque jamais, si bien que le bilan énergétique diminue. Lorsque l'animal reste en bilan énergétique positif, les teneurs en constituants du lait et en métabolites sanguins ne sont pas ou peu modifiées. Par contre, si ce bilan devient négatif, on observe des accroissements des teneurs en acides gras non estérifiés (AGNE) sanguins, du taux butyreux et de la proportion d'acides gras à longue chaîne du lait (reflétant une lipomobilisation accrue), et une diminution ( $-2 \mathrm{~g} / \mathrm{l}$ en moyenne dans 9 essais) du taux protéique, qui est en accord avec ce qui est observé dans les autres cas de sousalimentation énergétique (revue de Rémond, 1985).

\section{Essais de longue durée (plus de 10 semaines).}

On dispose des résultats publiés de 3 essais utilisant de l'hormone hypophysaire (Brumby et Hancock, 1955 ; Machlin, 1973 ; Peel et al., 1985), ainsi que d'un essai utilisant de l'hormone obtenue par recombinaison génétique (" somatotropine recombinée ") (Bauman et al., 1985). Un nombre croissant d'essais postérieurs ont par ailleurs fait l'objet de courtes communications lors de congrès (voir tabl. 2). II convient donc de rester très prudent dans l'interprétation et la généralisation des données du tableau 2, dont les conditions d'obtention sont très mal connues.

La production laitière augmente fortement $(+5,7 \mathrm{~kg} / \mathrm{j}$ en moyenne dans 15 essais, soit $+23 \%$ ) pendant toute la période des injections de somatotropine (tabl. 2). Les augmentations de production laitière sont plus fortes avec l'hormone recombinée (Bauman et al., 1982, 1985 ; Hutchison et al., 1986) qui possède un résidu méthionine supplémentaire, qu'avec l'hormone naturelle. L'ingestion de la ration n'augmente qu'après un temps de latence d'environ 6 semaines. Cette augmentation n'est en moyenne que de $1,2 \mathrm{~kg}$ de matière sèche $(\mathrm{MS}) / \mathrm{j}$, et elle ne permet pas de couvrir l'accroissement du niveau de production. II en résulte une diminution moyenne de 2,2 Mcal/j du bilan énergétique calculé des animaux. II est remarquable de constater que l'augmentation d'ingestion de $1,2 \mathrm{~kg} / \mathrm{j}$ est presque exactement celle que l'on peut prédire (Vérité et Journet, 1978) en comparant des vaches non traitées ayant des potentiels laitiers qui diffèrent de $5 \mathrm{~kg} / \mathrm{j}$ (Chalupa et al., 1987a). Une tendance comparable est observée chez des vaches qui augmentent leur production laitière lorsqu'elles sont traites trois fois par jour (De Peters et al., 1985).

L'effet "dose-réponse " plafonne au-delà d'injections supérieures à 25 unités/vache/jour. Dans 8 essais comparatifs la réponse est en effet de $6,2 \mathrm{~kg}$ de lait avec 25 unités, et de 6,5 kg avec 40-50 unités/jour.

Les expériences rapportées ci-dessus ont été effectuées pour la plupart en injectant quotidiennement la somatotropine aux animaux. Les essais récents sur I'hormone administrée sous une forme "retard", une ou deux fois par mois (indispensable à toute utilisation éventuelle sur le terrain) n'ont donné lieu, à notre connaissance, qu'à quelques publications préliminaires rapportant des augmentations moyennes de production laitière de 2 à 5 kg/j (Schockmel, 1986 ; McGuffey 
TABLEAU 2

Effets à long terme (plus de 10 semaines) d'injections de somatotropine (25 à 50 unités/j) sur la production laitière, l'ingestion de matière sèche et le bilan énergétique calculé,

chez la vache après le pic de lactation (injections journalières, sauf pour d-f-gl.

\begin{tabular}{|c|c|c|c|c|c|c|c|c|}
\hline \multirow[t]{2}{*}{ Références } & \multirow{2}{*}{$\begin{array}{l}n \\
\text { (a) }\end{array}$} & \multirow{2}{*}{$\begin{array}{l}\text { Durée } \\
\text { (jours) }\end{array}$} & \multirow{2}{*}{$\begin{array}{l}\text { Dose } \\
(\mathrm{mg} / \mathrm{j})\end{array}$} & \multicolumn{2}{|c|}{ Lot Témoin } & \multicolumn{3}{|c|}{$\begin{array}{l}\text { Effets de la somatotropine } \\
\text { (traité-témoin) }\end{array}$} \\
\hline & & & & PL (a) & MSI & $\mathrm{PL}$ & MSI & $\mathrm{BE}$ \\
\hline Brumby et Hancock, 1955. & 3 (b) & 84 & $50(p)$ & 13,1 & 12,3 (c) & $+5,8$ & $+0,7(\mathrm{c})$ & $-3,4$ \\
\hline Bauman et al., 1985 & 6 & 188 & & 27,9 & 21,9 & $+10,1$ & $+3,3$ & $-1,9$ \\
\hline Peel et al., $1985 \ldots$ & 5 & 147 * & 50 & 19,8 & 15,5 & $+3,5$ & $+1,6$ & $-0,3$ \\
\hline Baird et al., 1986 & 8 & $266 *$ & 25 & 25,7 & 21,3 & $+\quad 4,7$ & $+1,1$ & $-1,5$ \\
\hline Chalupa et al., 1986 & 8 & $260 *$ & 25 & 24,2 & 17,0 & $+5,3$ & $+0,5$ & $-2,9$ \\
\hline Hutchison et al., 1986 & 6 & 188 & 27 & 26,0 & - & $+7,3$ & 0 & $-4,9$ \\
\hline Soderholm et al., 1986a & 9 & $260 *$ & 25 & 28,5 & 21,8 & $+8,7$ & $+2,2$ & $-2,7$ \\
\hline Annexstad et al., 1987 & 7 & $259 *$ & 25 & 29,8 & 23,7 & $+7,0$ & $+3,7$ & $+0,9$ \\
\hline Burton et al., 1987 & 9 & $266^{*}$ & 25 & 26,7 & 19,5 & $+4,8$ & $+1,0$ & $-1,8$ \\
\hline Chalupa et al., 1987b & 30 & $-{ }^{*}$ & 25 & 27,7 & 20,2 & $+\quad 4,4$ & $+1,0$ & $-2,1$ \\
\hline Elvinger et al., 1987 & 9 & $273^{*}$ & 25 & 21,1 & - & $+8,2$ & 0 & $-5,7$ \\
\hline Thomas et al., 1987 & 20 & $259 *$ & 25 & 20,1 & - & $+4,8$ & $+1,3$ & $-1,6$ \\
\hline McGuffey et al., 1987a . & 7 & 84 & 46 (d) & 22,9 & 20,2 & $+\quad 4,1$ & $+0,8$ & $-1,7$ \\
\hline McGuffey et al., 1987b & $63(\mathrm{e})$ & 84 & 11 à 69 (f) & 26,4 & 19,9 & $+5,0$ & $+0,5$ & $-2,4$ \\
\hline Rémond et al., $1987 \ldots$ & 24 & 70 & $36(\mathrm{~g})$ & 23,9 & 16,8 & $+\quad 2,2$ & 0 & $-1,5$ \\
\hline \multirow{2}{*}{\multicolumn{3}{|c|}{$\begin{array}{l}\text { Réponse moyenne } \ldots \\
( \pm \text { écart-type }) \ldots \ldots\end{array}$}} & & & & $\begin{array}{l}+5,7 \\
+\end{array}$ & $+1,2$ & $-2,2$ \\
\hline & & & & & & $( \pm 2,1)$ & $( \pm 1,1)$ & $( \pm 1,6)$ \\
\hline
\end{tabular}

(a) Abréviations comme dans le tableau 1. (b) Couples de jumelles. (c) Matière organique digestible. (d) 4 injections mensuelles de $960 \mathrm{mg}$. (e) 9 lots de 7 vaches. (f) Injections tous les 14, 21 ou 28 jours de 320,640 ou $960 \mathrm{mg}$. (g) Injections bimensuelles de $500 \mathrm{mg}$. (avec l'aimable autorisation de la société Monsanto) ( $p$ ) Somatotropine hypophysaire (recombinée dans les autres cas).

* Injections effectuées à partir de la $5^{\mathrm{e}}$ semaine de lactation (à partir de la $8^{\mathrm{e}}$ semaine au moins dans les autres cas).

et al., 1987a, b ; Rémond et al., 1987). Les réponses sont toutefois généralement décroissantes au cours de l'intervalle entre deux injections, ce qui laisse entrevoir des effets plus importants avec l'amélioration éventuelle des formes " retard " actuelles (Huber, 1987).

Dans les essais rapportés dans le tableau 2, il n'existait généralement pas de changements de composition du lait par rapport au lot témoin, car les vaches sont restées en moyenne en bilan énergétique positif. Une augmentation du taux butyreux et une diminution du taux protéique $(-0,8 \mathrm{~g} / \mathrm{kg})$ peuvent toutefois être observées lorsque l'augmentation du niveau d'ingestion est insuffisante (Rémond et al., 1987 ; Simkins, 1987).

Les vaches ayant reçu la somatotropine présentent parfois un moindre gain de poids pendant la lactation que les vaches témoins (Bauman et al., 1985 ; Burton et al., 1987 ; Chalupa et al., 1987b ; Thomas et al., 1987). Ceci n'est toutefois pas le cas dans d'autres essais de longue durée (Brumby et Hancok, 1955 ; Peel et al., 1985 ; Soderholm et al., 1986b ; Chalupa et al., 1987a ; McGuffey et al., 1987a ; Thomas et al., 1987). 
L'absence de différences de poids vif ne permet pas, cependant, d'affirmer qu'il n'existe pas de différences de composition corporelle entre les animaux témoins ou traités. Les quelques données préliminaires existantes à ce sujet suggèrent que les vaches ayant reçu de la somatotropine sont plus maigres en fin d'expérience que les vaches témoins (tabl. 3). Ceci semble logique puisque, si I'on admet que les rendements des différentes étapes d'utilisation de l'énergie ne sont pas modifiés par la somatotropine (cf. ci-dessous), un déficit de 2,2 Mcal/j par rapport au lot témoin (tabl. 2) correspondrait à un dépôt lipidique pendant la lactation diminué de 40 à $45 \mathrm{~kg}$ environ. Toutefois, dans plusieurs autres essais à long terme, on n'a pas observé de différences dans les teneurs en AGNE sanguins (Bauman et al., 1982 ; Hutchison et al., 1986), et dans les notes d'état corporel (appréciation visuelle ou par les maniements) (Machlin, 1973 ; Peel et al., 1985) malgré de fortes augmentations de production laitière relativement à l'augmentation du niveau d'ingestion. Des pertes de poids ont par ailleurs été observées chez les vaches traites trois fois par jour, dont l'augmentation d'ingestion ne couvre pas les besoins liés au lait supplémentaire (De Peters et al., 1985).

Un allongement de l'intervalle vêlage - insémination fécondante a été rapporté dans plusieurs essais, notamment avec de fortes doses de somatotropine (50 unités par jour) injectées dès la $5^{e}$ semaine de lactation (Burton et al., 1987 ; Elvinger et al., 1987 ; Thomas et al., 1987). Cet allongement est toutefois comparable à celui qui est observé lorsque le potentiel de production augmente chez des vaches non traitées (Bauman, 1987).

La réponse à la somatotropine est parfois plus faible chez les primipares (Marsh et al., 1987), mais pas dans tous les essais (Rémond et al., 1987). Des

\section{TABLEAU 3}

Effets à long terme (6 à 9 mois) d'injections de somatotropine sur la composition corporelle des vaches.

\begin{tabular}{|c|c|c|}
\hline & $\begin{array}{l}\text { Soderholm et al. } \\
\qquad(1986 \mathrm{~b})\end{array}$ & $\begin{array}{l}\text { R. Vérité et } \\
\text { Y. Chilliard } \\
\text { (non publié) (d) }\end{array}$ \\
\hline Injection de somatotropine & $\begin{array}{r}25 \mathrm{mg} / \mathrm{j} \\
\times 260 \mathrm{j}\end{array}$ & $\begin{array}{l}6 \text { injections } \\
\text { mensuelles de } \\
960 \mathrm{mg}\end{array}$ \\
\hline \multicolumn{3}{|l|}{ Effets de la somatotropine (traité-témoin) sur : } \\
\hline $\begin{array}{l}\text { - la production laitière }(\mathrm{kg} / \mathrm{j}) \\
\text { - la matière sèche ingérée }(\mathrm{kg} / \mathrm{j}) \\
\text { - le bilan énergétique calculé }(\mathrm{Mcal} / \mathrm{j}) \\
\text { - le poids vif }(\mathrm{kg}) \\
\text { - la teneur en lipides corporels }(\%) \text { (a) } \\
\text { - les AGNE sanguins } \\
\text { - la note d'état corporel (échelle de } 0 \text { à } 5)\end{array}$ & $\begin{array}{l}+8,7 \\
+2,2 \\
-2,7 \\
N S \\
-6,4(b, c) \\
+30 \%(b) \\
-1,0(b)\end{array}$ & $\begin{array}{c}-1,0 \\
-18,2 \\
-4,5 \text { à } 6,5(c, e) \\
+97 \% \\
-0,2\end{array}$ \\
\hline
\end{tabular}

(a) Estimée à partir de l'espace de diffusion de l'eau deutériée. (b) Les auteurs ne précisent pas s'il s'agit des valeurs à la fin du traitement, ou des moyennes des mesures à différents stades. Cinq à neuf vaches par lot, selon les mesures. (c) Soit environ -30 à $-40 \mathrm{~kg}$ de lipides. (d) 6 à 7 vaches traitées, et 8 à 10 vaches témoins (avec l'aimable autorisation de la société Lilly). (e) Selon le mode de calcul. NS $=$ pas de différence significative. 
interactions entre somatotropine, croissance et galactopoièse sont probables chez ces animaux. Des réponses très faibles ont été rapportées lorsque les conditions environnementales ou de conduite du troupeau sont défavorables (Mollett et al., 1986). La réponse ne semble pas être liée étroitement au génotype et au phénotype (niveau de production) des animaux, et l'on observe parfois une plus forte réponse ches les faibles productrices (Leitch et al., 1987 - tabl. 4).

\section{TABLEAU 4}

Accroissements relatifs de production laitière selon la durée des périodes d'injections quotidiennes de somatotropine, le stade de lactation, le niveau de production et le bilan énergétique des vaches.

\begin{tabular}{|c|c|c|c|c|}
\hline \multirow{3}{*}{$\begin{array}{c}\text { Stade de lactation, niveau } \\
\text { de production laitière et bilan } \\
\text { énergétique (BE) du lot } \\
\text { témoin }\end{array}$} & \multicolumn{4}{|c|}{ Durée du traitement } \\
\hline & \multicolumn{2}{|c|}{ Moins de 35 jours } & \multicolumn{2}{|c|}{ de 49 à $190 \mathrm{j}$} \\
\hline & $\bar{x}( \pm s x)$ & Nombre d'essais & $\bar{x}( \pm s x)$ & Nombre d'essais \\
\hline Moins de 3 mois & $6 \%( \pm 4)$ & $5(a)$ & - & - \\
\hline \multicolumn{5}{|l|}{$\begin{array}{l}\text { Trois à sept mois, et plus } \\
\text { de } 15 \mathrm{~kg} / \mathrm{j}:\end{array}$} \\
\hline$-\mathrm{BE} \leq 0,4 \mathrm{Mcal} / \mathrm{j}$ & $12 \%( \pm 1)$ & $5(b)$ & - & - \\
\hline$-\mathrm{BE}>4.0 \mathrm{Mcal} / \mathrm{j}$ & $18 \%( \pm 6)$ & $7(\mathrm{c})$ & $24 \%( \pm 7)$ & $6(d)$ \\
\hline $\begin{array}{l}\text { Plus de } 7 \text { mois, ou moins de } \\
15 \mathrm{~kg} / \mathrm{j}\end{array}$ & $30 \%( \pm 9)$ & $6(e)$ & $40 \%( \pm 12)$ & $3(f)$ \\
\hline
\end{tabular}

(a) Bines et Hart (1982) ; Mc Dowell et al. (1983) ; Chalupa et al. (1985) ; Richard et al. (1985) : Schneider et al. (1987). (b) Voir tableau 1 et Bines et al. (1980). (c) Voir tableau 1. (d) Voir tableau 2 et Kik et Cook (1986). (e) Voir tableau 1 et Brumby et Hancock (1955). (f) Brumby et Hancock (1955) ; Machlin (1973) ; Bauman et al. (1985).

\section{Mécanismes d'action de la somatotropine}

\section{Effets possibles au niveau de la glande mammaire.}

La sécrétion des constituants du lait est conditionnée par au moins quatre paramètres : a) le nombre et la durée de vie des cellules sécrétrices; b) le flux sanguin mammaire ; c) la disponibilité artérielle en métabolites précurseurs des constituants du lait; d) l'activité métabolique des cellules sécrétrices.

a) Nombre et durée de vie des cellules sécrétrices. - Ces aspects sont peu connus en raison des difficultés inhérentes à leur étude. La somatotropine exogène stimule la croissance du parenchyme mammaire chez la génisse autour de la puberté (Sejrsen et al., 1986) et l'agnelle pré-pubère (Johnsson et al., 1986). II n'existe pas de données sur d'éventuelles variations du nombre et de la durée de vie des cellules mammaires chez l'animal traité en pleine lactation.

Toutefois, Perier et al. (1987) rapportent que des injections de somatrocrinine (GRF), qui augmentent la sécrétion de somatotropine endogène, pourraient stimuler durablement la croissance mammaire chez la brebis non gravide au cours 
d'une induction hormonale de lactation. Ceci peut être rapproché des effets de I'IGF-1 (Insulin-like Growth Factor, ou Somatomédine C), qui pourrait être un des médiateurs des effets métaboliques de la somatotropine, et qui stimule à faible dose in vitro la synthèse de I'ADN par le tissu mammaire de vaches et de brebis gravides ou en lactation (Baumrucker 1986a, b ; Winder et Forsyth, cités par Johnsson et Hart, 1986). Des injections de somatotropine à des génisses avant mise bas ont toutefois donné lieu à des résultats positifs ou nuls (revue de Gluckman et al., 1987). Les effets de la somatotropine in vivo, en pleine lactation, sont de plus entièrement réversibles et perdus en 2 à 4 jours après l'arrêt du traitement, ce qui suppose d'autres mécanismes d'action.

b) Flux sanguin mammaire. - Les flux sanguins cardiaque et surtout mammaire augmentent notablement lors d'injections de somatotropine chez la vache et la chèvre, ainsi que le prélèvement des métabolites précurseurs du lait (revues de Johnsson et Hart, 1986 ; Chilliard, 1987 ; Peel et Bauman, 1987). II n'est toutefois pas encore possible de déterminer si cette augmentation est la cause ou la conséquence de l'augmentation de l'activité sécrétrice des cellules mammaires.

c) Disponibilité artérielle en métabolites. - La disponibilité artérielle en métabolites précurseurs des constituants du lait peut être accrue en raison d'une augmentation du niveau d'ingestion, et/ou d'une épargne de nutriments par les tissus périphériques extra-mammaires (cf. ci-dessous).

Des infusions post-ruminales de glucose et de caséine, ou la supplémentation de la ration en matières grasses, n'ont pas permis d'obtenir des augmentations de la sécrétion lactée comparables à celles permises par la somatotropine (Peel et al., 1982 ; Lough et al., 1984 ; Schneider et al., 1987). II en est de même lorsque la ration est supplémentée à l'aide de bicarbonate de sodium ou d'acides gras volatils à chaîne ramifiée (Kik et Cook, 1986 ; Chalupa et al., 1984a, 1985). De même, une différence d'apport de concentré énergétique $(+1,4 \mathrm{~kg} / \mathrm{j})$ n'a pas modifié la réponse à la somatotropine (Rémond et al., 1987).

La concentration artérielle des métabolites sanguins ne semble pas être un facteur limitant du métabolisme lorsque l'animal n'est pas sous-alimenté (revue de Davis et Collier, 1985). La réponse maximale à la somałotropine, en pourcentage du niveau de production initial, est par ailleurs observée chez les faibles productrices ou en fin de lactation, lorsque les besoins en nutriments sont faibles (tabl. 4). II est donc probable que la réponse à la somatotropine ne résulte pas en premier lieu d'un accroissement de la disponibilité en substrats circulants.

d) Activité métabolique des cellules sécrétrices. - Les considérations qui précèdent amènent à penser que c'est une stimulation de l'activité métabolique des cellules mammaires qui serait le principal facteur permettant les augmentations de sécrétion lactée induites par la somatotropine. Ainsi, la teneur du lait en alphalactalbumine (protéine qui intervient dans la synthèse du lactose) est accrue proportionnellement à la dose de somatotropine injectée (Eppard et al., 1985b). II n'existe que peu de mesures d'activités enzymatiques ou métaboliques effectuées in vivo. Les activités lipoprotéine-lipasiques du tissu mammaire et du lait ne sont 
pas modifiées chez les vaches recevant de la somatotropine (Lough et al., 1986), alors que l'activité de l'acétyl-CoA synthétase est augmentée chez la chèvre (Marinez et al., 1976). Les mesures d'activités enzymatiques du tissu mammaire sont toutefois difficiles à interpréter et à extrapoler in vivo (Baldwin et Yang, 1974 ; Chilliard et al., 1986).

Le plafonnement des accroissements de production laitière avec les fortes doses de somatotropine pourrait par ailleurs être relié à une saturation de la capacité de stockage mammaire entre deux traites, puisque l'augmentation de la pression intramammaire peut ralentir l'activité sécrétrice des cellules (Gluckman et al., 1987).

e) Mécanisme d'action éventuel. - De nombreux résultats expérimentaux montrent que la somatotropine de ruminant $n^{\prime} a$ pas d'effet direct sur le tissu secrétoire mammaire de ces espèces :

- elle n'augmente pas la sécrétion lactée lorsqu'elle est infusée dans une demimamelle (McDowell et Hart, 1984) ;

- elle n'a pas d'effet galactopoiétique sur le tissu mammaire cultivé in vitro (Gertler et al., 1983 ; Baumrucker, 1985 ; Keys et Capuco, 1985 ; Fekry et al., 1986) ;

- elle ne semble pas avoir de récepteurs spécifiques dans ce tissu (Gertler et al., 1984 ; Akers, 1985 ; Keys et Djiane, 1987).

Une des hypothèses émises actuellement pour expliquer cette contradiction apparente est que la somatotropine stimule la production de somatomédines (IGFs) par le foie, et que celles-ci modifieraient le métabolisme de certains tissus, dont la glande mammaire.

Le foie de ruminant possède en effet des récepteurs de la somatotropine (Keys et al., 1986 ; Keys et Djiane, 1987) et les teneurs plasmatiques en IGF-1 augmentent en quelques heures après injection de somatotropine (Davis et al., 1987). Les tissus mammaires bovin (Campbell et Baumrucker, 1986 ; Dehoff et al., 1986) et ovin (Disenhaus et al., 1988) possèdent par ailleurs des récepteurs aux IGFs et les variations de ces récepteurs tissulaires pourraient être le facteur déterminant de I'effet biologique des IGFs, contrairement aux teneurs plasmatiques dont la signification est incertaine.

Cependant, chez des brebis en états physiologiques variables (gravides, en lactation, ou induites en lactation et traitées au GRF) il n'existe pas de relations étroites entre les variations de la somatotropine circulante et celles du nombre ou de I'affinité des récepteurs des IGFs dans la glande mammaire (C. Disenhaus et J. Djiane, comm. pers.). II n'existe en outre pas d'arguments expérimentaux montrant un effet des IGFs ou de leurs récepteurs sur l'activité sécrétrice des cellules mammaires, alors que des effets sur la multiplication et la différenciation des cellules sécrétrices sont probables, en interaction avec d'autres hormones (prolactine, ...) (Baumrucker, 1986a, b ; Disenhaus et al., 1988). Les effets d'injections de somatomédines ne sont par ailleurs pas connus et, chez le rat, les effets galactopoiétiques de la prolactine et de la somatotropine ne semblent pas être dus à l'IGF-1 (Madon et al., 1986). 


\section{Effets possibles sur le métabolisme général.}

L'accroissement du prélèvement des nutriments qu'implique l'augmentation de production laitière induite par la somatotropine n'est que partiellement couvert par un accroissement du niveau d'ingestion. On a donc cherché à mettre en évidence des mécanismes d'épargne ou de redistribution des nutriments entre tissus, susceptibles d'expliquer ce phénomène.

a) Efficacité d'utilisation de la ration. - Les coefficients de digestibilité de l'énergie et de l'azote sont légèrement augmentés (Peel et al., 1981, 1985) ou légèrement diminués (Tyrrell et al., 1982 ; Eisemann et al., 1986a) consécutivement à l'administration de somatotropine. On peut calculer qu'une augmentation de 2 points de la digestibilité de l'énergie (rarement significative lors de ce type de mesures) représenterait un apport d'énergie permettant de produire environ $320 \mathrm{~kg}$ de lait supplémentaire en 200 jours, ou un dépôt d'environ 20 à $25 \mathrm{~kg}$ de lipides corporels. II est donc nécessaire de mieux connaître ces éventuelles variations pour interpréter les essais zootechniques, notamment en raisonnant à même niveau d'ingestion et/ou de production laitière.

Par ailleurs, l'administration de somatotropine ne semble pas changer le besoin d'entretien ou l'efficacité d'utilisation de l'énergie métabolisable pour la sécrétion lactée ou les dépôts tissulaires, in vivo et in vitro (Tyrrell et al., 1982 ; Eisemann et al., 1986a ; Mc Bride et al., 1987). L'efficacité globale d'utilisation de la ration n'augmente donc qu'en raison de la dilution du besoin d'entretien dans le besoin total (entretien et production laitière).

b) Métabolisme glucidique. - Dans des essais à court terme où la somatotropine augmente la production de lait et de lactose sans accroître le niveau d'ingestion, la fourniture supplémentaire de glucose à la mamelle est permise par une diminution de l'oxydation extra-mammaire de glucose, qui pourrait expliquer jusqu'à $30 \%$ de l'accroissement de la sécrétion de lactose (Bauman et al., 1987), et/ou par une augmentation de la néoglucogenèse, puisque la perte irréversible de glucose augmente (McDowell et al., 1983 ; Bauman et al., 1987).

L'augmentation de la néoglucogenèse n'étant dans ce cas pas permise par un accroissement des entrées des précurseurs exogènes (propionate ou acides aminés), elle peut résulter soit d'une réduction de l'oxydation hépatique de ces précurseurs, soit d'une utilisation accrue de précurseurs endogènes (glycérol, lactate, acides aminés). Pocius et Herbein (1986) ont montré que le potentiel de néoglucogenèse augmente dans le foie de vaches traitées à la somatotropine, sans que l'oxydation du propionate soit réduite. Par ailleurs, le glycérol libre provenant des tissus adipeux pourrait fournir jusqu'à $27 \%$ des besoins supplémentaires de glucose (Bauman et al., 1987).

La réduction de l'oxydation du glucose, quant à elle, intervient notamment dans les muscles, où le prélèvement de ce métabolite peut être réduit de $85 \%$ dans certains essais effectués in vivo (McDowell et al., 1984). Cet effet " diabétogène " de l'hormone (Hart, 1983) se traduit parfois par une augmentation de la glycémie chez des vaches faibles productrices, alors que celle-ci n'augmente pas chez les fortes productrices qui utilisent entièrement le glucose ainsi épargné pour la sécrétion lactée (Bines et al., 1980 ; Johnsson et Hart, 1986). 
c) Métabolisme azoté. - Lorsque les vaches sont en bilans énergétique et azoté négatifs, les accroissements des productions de lait et de protéines s'accompagnent d'une chute du taux protéique du lait, suggérant que la fourniture en acides aminés est limitante et que la mobilisation des protéines corporelles est faible, bien que significative (Tyrrell et al., 1982). Cet aspect mériterait d'être mieux quantifié, mais il est cohérent avec les observations effectuées sur animaux en croissance où la somatotropine favorise le dépôt des protéines corporelles et diminue la protéolyse et l'oxydation des acides aminés et l'excrétion d'azote urinaire, ces effets étant probablement dus en partie aux IGFs (Eisemann et al., 1986a, b ; revues de Etherton et Kensinger, 1984, Hart et Johnsson, 1986 ; Gluckman et al., 1987).

La diminution de l'excrétion d'azote urinaire a par ailleurs été confirmée chez la vache en lactation et en bilan azoté positif (Bines et al., 1980 ; McDowell et al., 1983 ; Chalupa et al., 1984b), mais pas lorsque ce bilan est négatif (Peel et al., 1981 ; Tyrrell et al., 1982 ; McDowell et al., 1983).

Les données existantes permettent donc de penser que chez l'animal en bilan azoté positif, la somatotropine ou ses médiateurs facilitent la sécrétion des protéines du lait en inhibant l'oxydation des acides aminés, alors que chez l'animal en bilan négatif, une mobilisation limitée des protéines corporelles permettrait de sécréter plus de protéines, mais n'empêche pas une diminution du taux protéique.

d) Métabolisme lipidique. - Au cours des essais dans lesquels l'administration de somatotropine induit un passage des vaches en bilan énergétique négatif, on observe une lipomobilisation qui se traduit par une augmentation des teneurs en AGNE sanguins et de leur perte irréversible, et une augmentation de la sécrétion des acides gras à 18 atomes de carbone par la mamelle. Ces modifications ne sont pas observées lorsque les vaches restent en bilan énergétique positif, mais la diminution de ce bilan (cf. tabl. 1, 2, 3), permet de penser qu'il y a alors une moindre lipogénèse dans les tissus adipeux, ce qui réduit leur concurrence pour les précurseurs lipogéniques vis-à-vis de la mamelle (revues de Johnsson et Hart, 1986 ; Chilliard, 1987 ; Peel et Bauman, 1987).

La somatotropine a probablement des effets lipolytiques et antilipogéniques directs sur le tissu adipeux, comme l'ont montré des études réalisées in vitro sur tissu adipeux ou adipocytes de rat, de porc, de mouton et de bovins, avec les somatotropines humaine, porcine, ovine et bovine (revues de Etherton et Kensinger, 1984 ; Hart et al., 1984 ; Chilliard, 1987). Si l'on excepte un effet lipogénique à très court terme, ces hormones semblent avoir un effet à long terme en modifiant le potentiel métabolique (les synthèses d'enzymes, de récepteurs...) du tissu adipeux de façon à réduire les réponses aux stimuli lipogéniques (insuline) et à accentuer les réponses aux stimuli lipolytiques (adrénaline) (Goodman et Schwartz, 1974 ; Etherton et Kensinger, 1984 ; Vernon, 1982, 1986 ; McCutcheon et Bauman, 1986b ; Walton et Etherton, 1986).

Le métabolisme lipidique ne semble pas être notablement altéré dans le foie. En effet, ni le potentiel cétogénique du foie in vitro (Pocius et Herbein, 1986), ni les teneurs en phospholipides et en cholestérol circulants (Bitman et al., 1984) ne sont modifiés. Le flux accru d'AGNE serait donc en grande partie utilisé, soit par la lipogénèse mammaire (cf. ci-dessus), soit comme source d'énergie se subs- 
tituant au glucose et aux acides aminés, qui seraient ainsi épargnés dans le métabolisme oxydatif (Bauman et al., 1987 ; Eisemann et al., 1986b), en particulier musculaire (McDowell et al., 1984).

\section{Interactions métaboliques et hormonales.}

La somatotropine exogène permet un accroissement très important du niveau de production laitière par le biais de modifications cordonnées du métabolisme dans l'ensemble des tissus et organes de la femelle. En effet, cette hormone n'a pas seulement une action galactopoïétique, qui déclencherait une mobilisation ou un moindre dépôt des tissus périphériques par des réactions homéostatiques " normales", consécutives au drainage accru de nutriments par la mamelle (fig. 1). On doit envisager ici une régulation globale de type téléophorétique (Bauman et Currie, 1980 ; Chilliard, 1986) (fig. 2), dans laquelle la somatotropine aurait des effets sur le tissu mammaire (peut-être par le biais de I'IGF-1 dont elle stimulerait la sécrétion par le foie), mais aussi sur le tissu adipeux, le foie, les muscles et peut-être les os et la sphère de régulation de l'ingestion (à plus long terme), de façon à soutenir la fonction de sécrétion lactée. La plupart des mécanismes sont inconnus, et il faut dans un premier temps chercher à distinguer les effets métaboliques qui résultent d'un effet direct de la somatotropine ou de ses dérivés après métabolisation tissulaire, de ceux qui sont régulés par des messagers du type des somatomédines. Ces dernières pourraient être un des médiateurs des effets anaboliques de la somatotropine, dont les effets cataboliques seraient par contre plus directs (?).

Par ailleurs, l'action de la somatotropine s'effectue en interaction avec d'autres effets hormonaux. II faut souligner que l'homéostase du milieu intérieur est bien maintenue chez l'animal traité par la somatotropine, puisque les teneurs en métabolites et en hormones plasmatiques sont généralement inchangées et

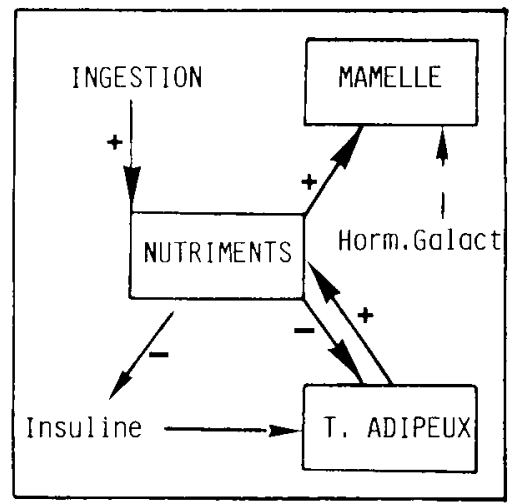

FIG. 1. - Galactopoïse et homéostase. Les hormones galactopoiétiques stimulent le métabolisme mammaire et le drainage des nutriments par la mamelle, la glycémie et l'insulinémie diminuent, le catabolisme augmente et l'anabolisme diminue dans le tissu adipeux. Ce schéma ne permet toutefois pas de rendre compte de toutes les observations expérimentales. 
qu'il n'a pas été rapporté de troubles métaboliques systématiques liés à l'apport de somatotropine (Bauman et McCutcheon, 1986 ; Eppard et al., 1987). Dans le cas du tissu adipeux, par exemple, la somatotropine semble (à "long terme ") modifier le potentiel de réponse tissulaire aux régulations homéostatiques à court terme (insuline, catécholamines) dans un sens qui réduit sa concurrence vis-à-vis de la glande mammaire, et/ou accroît la mobilisation des substrats lipidiques (fig. 2). La régulation homéostatique est donc maintenue dans son essence bien que téléophorétiquement décalée par rapport à la régulation « normale ». Un phénomène comparable est observé chez la femelle en début de lactation ne recevant pas de somatotropine exogène, où le métabolisme du tissu adipeux reste très lié au bilan énergétique (Chilliard et al., 1987) bien que moins sensible à l'insuline (revue de Chilliard, 1987).

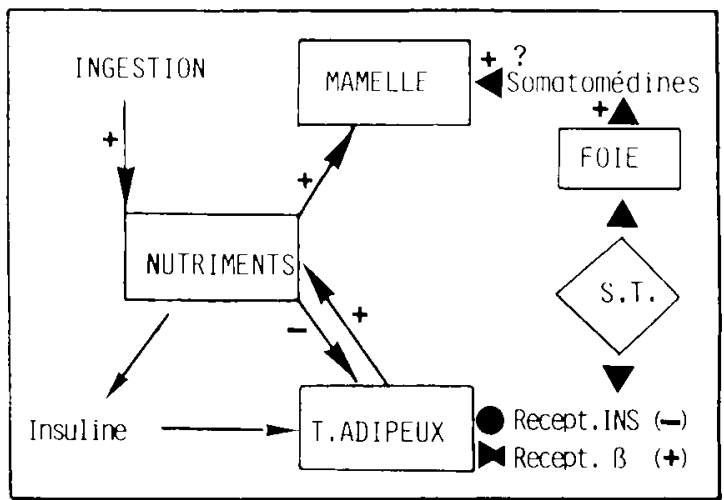

FIG. 2. - Mécanismes téléophorétiques (Bauman et Currie, 1980; Chilliard, 1986). Les régulations à long terme par les hormones téléophorétiques modifient le potentiel métabolique des différents tissus de façon à assurer la priorité de la fonction de lactation. Les régulations homéostatiques demeurent, mais seraient décalées vers des seuils de sensibilités tissulaires qui favorisent la lipomobilisation et la néoglucogénèse hépatique, et freinent la lipogénèse des tissus adipeux et l'oxydation musculaire du glucose, sans que la sécrétion d'insuline ne soit nécessairement modifiée.

S.T. = somatotropine : Recept. INS $(\beta)=$ récepteurs de l'insuline ( $\beta$-adrénergiques).

II est en outre possible que la réponse immédiate de l'animal à la somatotropine soit modulée par l'état nutritionnel et hormonal. En effet, les récepteurs hépatiques de l'hormone, et probablement la production de somatomédines, sont sous dépendance insulinique chez le rat (Baxter et al., 1980 ; Spencer, 1985 ; Maes et al., 1986) et le veau (Coxam et al., 1987 et comm. pers.). La situation est peut-être comparable chez les ruminants puisque les teneurs en somatomédines circulantes sont faibles chez les bovins sous-alimentés (Gluckman et al., 1987) et chez la vache en début de lactation malgré des teneurs élevées en somatotropine (Falconer et al., 1980). Cette " résistance à la somatotropine » pourrait expliquer les faibles réponses de production laitière lorsque la somatotropine est injectée en début de lactation ou chez l'animal sous-alimenté (tabl. 4). Ceci n'a toutefois pas 
été vérifié chez la chèvre sous-alimentée en pleine lactation, qui répond bien à des injections de GRF (D. Sauvant et al., comm. pers.). Par ailleurs, le renouvellement de la somatotropine est réduit chez le ruminant à jeûn, mais pas en début de lactation, où une éventuelle résistance à la somatotropine reste à démontrer (revue de Gluckman et al., 1987).

D'autres hypothèses, qui restent à vérifier, sont aussi suggérées par les données du tableau 4 :

10) la somatotropine endogène serait moins limitante en début de lactation et chez les plus fortes productrices (+ de $15 \mathrm{~kg} / \mathrm{j})$;

$2^{\circ}$ ) la fourniture en certains nutriments (acides aminés, glucose...) serait plus limitante à ce stade ;

$\left.3^{\circ}\right)$ la durée de vie des cellules mammaires serait accrue par la somatotropine, ce qui expliquerait l'ampleur des effets à long terme, tout au moins avant que la gestation ne soit trop avancée.

La complexité du phénomène est probablement encore plus grande, si l'on envisage les régulations possibles des synthèses des somatomédines et de leurs récepteurs dans différents tissus (foie, os, muscles, mamelle) en interaction avec l'insuline, les hormones thyroïdiennes, les glucocorticoïdes, la prolactine et les œstrogènes (Etherton et Kensinger, 1984 ; Spencer, 1985 ; Disenhaus et al., 1988 ; Gluckman et al., 1987 ; Coxam et al., 1987 et comm. pers.). Ce qui reflète, en définitive, le haut niveau d'intégration, à possibilités d'amplifications et sécurités multiples, atteint par la fonction de lactation chez les mammifères.

\section{Conclusion}

Des injections de somatotropine augmentent spectaculairement la production laitière des ruminants, et de façon variable selon la durée des périodes d'injections, l'origine et la forme de présentation de l'hormone, les doses injectées et le stade de lactation. Les interactions avec l'espèce, la race, le potentiel de production et l'âge des animaux sont encore mal connues.

La somatotropine et ses médiateurs modifient simultanément le métabolisme mammaire et le potentiel métabolique des autres tissus et organes (téléophorèse), sans compromettre les régulations homéostatiques assurant à court terme un fonctionnement normal de l'organisme. Les résultats d'expériences à long terme suggèrent que les vaches traitées à la somatotropine présentent des modifications zootechniques, métaboliques et physiologiques comparables à celles de vaches non traitées ayant un potentiel laitier supérieur (Peel et Bauman, 1987).

Les vaches recevant de la somatotropine tendent de ce fait à présenter un bilan nutritionnel (ingéré - besoins) inférieur à celui des vaches témoins, ce qui peut soit accroître la mobilisation de leurs réserves corporelles, soit limiter le dépôt de celles-ci. Il importe donc de veiller particulièrement à la qualité (ingestibilité et valeur nutritive) des rations distribuées aux vaches traitées. Les facteurs nutritionnels ne semblent toutefois pas expliquer entièrement la variabilité interessais des réponses à la somatotropine. Plusieurs considérations amènent à déconseiller son utilisation pendant les 6 premières semaines de lactation : elle est 
alors moins efficace, et pourrait accroître les troubles de la reproduction liés à un trop grand décalage entre l'ingéré et les besoins de l'animal. De même, l'utilisation de somatotropine pourrait poser des problèmes chez des vaches trop maigres en fin de lactation, chez lesquelles une reconstitution suffisante des réserves corporelles s'impose avant le tarissement.

On ne dispose que de très peu d'éléments sur les effets d'une utilisation répétée de somatotropine pendant plusieurs lactations, sur le potentiel mammaire, sur les réserves corporelles lipidiques, protéiques et minérales, sur la santé et la reproduction des vaches. La généralisation de son utilisation en élevage pourrait en outre entraîner des modifications importantes de la filière lait (élevages, relations avec les industries d'amont et d'aval, schémas de sélection des reproducteurs), ... comme le suggère l'étude de Mix (1987) appliquée au contexte économique des U.S.A.

Par ailleurs, on devra évaluer à l'avenir différentes stratégies possibles pour la valorisation du cheptel laitier à l'aide de manipulations de l'axe somatotrope hypophysaire : chez la génisse nullipare, chez l'adulte en fin de gestation, ou pendant la lactation descendante seulement ? avec quelle forme " retard " ou après quelles modifications moléculaires des somatotropines actuellement disponibles ? en stimulant la sécrétion endogène par des injections de somatocrinine (GRF) ou en immunisant l'animal contre la somatostatine, qui inhibe la sécrétion de somatotropine? en produisant des animaux transgéniques ? (Hart et Johnsson, 1986).

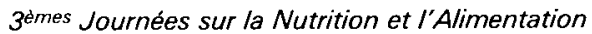
des Herbivores, I.N.R.A., Paris, 26 et 27 mars 1987.

Remerciements. - Je tiens à remercier Mmes R. Demaneche, L. Souchet et $Y$. Fournier pour la dactylographie du manuscrit, ainsi que R. Jarrige, J. Djiane, C. Disenhaus, D. Sauvant, J. P. Barlet, B. Rémond et J. Charrier pour la relecture de ce texte.

\section{Références}

AKERS R. M., 1985. Lactogenic hormones: binding sites, mammary growth, secretory cell differentiation, and milk biosynthesis in ruminants. J. Dairy Sci., 68, 501-519.

ANNEXSTAD R. J., OTTERBY D. E., LINN J. G., HANSEN W. P., SODERHOLM C. G., EGGERT R. G., 1987. Responses of cows to daily injections of recombinant bovine somatotropin (BST) during a second consecutive lactation. J. Dairy Sci., 70 (suppl. 1), 176 (Abstr.).

BAIRD L. S., HEMKEN R. W., HARMON R. J., EGGERT R. G., 1986. Response of lactating dairy cows to recombinant bovine growth hormone (rbGH). J. Dairy Sci, 69 (suppl. 1), 118 (Abstr.).

BALDWIN R. L., YANG Y. T., 1974. Enzymatic and metabolic changes in the development of lactation. In Lactation. A comprehensive treatise. Vol. I, p. 349-411 (LARSON B. L., SMITH V. R., Eds), Acad. Press, N.Y.

BARNES M. A., KAZMER G. W., AKERS R. M., PEARSON R. E., 1985. Influence of selection for milk yield on endogenous hormones and metabolites in Holstein heifers and cows. $J$. anim. Sci., 60, 271-284.

BAUMAN D. E., 1987. Bovine somatotropin: the Cornell experience. In National invitational workshop on bovine somatotropin (St Louis, USA), 46-56.

BAUMAN D. E., CURRIE W. B., 1980. Partitioning of nutrients during pregnancy and lactation : a review of mechanisms involving homeotatis and homeorhesis. J. Dairy Sci., 63, 1514-1529. 
BAuman D. E., Degeeter M. J., PEel C. J., LANZA G. M., GOREWIT R. C., HAMMOND R. W., 1982. Effects of recombinantly derived bovine growth hormone (bGH) on lactational performance of high yielding dairy cows. J. Dairy Sci., 65 (Suppl. 1), 121 (Abstr.).

BAUMAN D. E., EPPARD P. J., DegeETER M. J., LANZA G. M., 1985. Responses of highproducing dairy cows to long-term treament with pituitary somatotropin and recombinant somatotropin. J. Dairy Sci., 68, 1352-1362.

BAUMAN D. E., MCCUTCHEON S. N., 1986. The effects of growth hormone and prolactin on metabolism. In Proc. VI int. Symp. ruminant Physiol. : Control of digestion and metabolism in ruminants (MILLIGAN L. P., GROVUM W. L., DOBSON A. Eds), Reston Publ. Co. Inc. Reston, VA. (1984). Ch 23, 436-455.

BAUMAN D. E., PEEL C. J., STEINHOUR W. D., REYNOLDS P. J., TYRRELL H. F., BROWN A. C. G., HAALAND G. L., 1987. Effect of growth hormone on metabolism of lactating dairy cows : Influence on rates of irreversible loss and oxidation of glucose and nonesterified fatty acids. Cités par PEEL et BAUMAN, 1987.

BAUMRUCKER C. R., 1985. Growth hormone does not directly affect bovine mammary tissue growth nor lactating acini milk production in culture. J. Dairy Sci., 68 (suppl. 1), 106 (Abstr.).

BAUMRUCKER C. R., 1986a. Insulin like growth factor 1 (IGF-1) and insulin stimulates lactating bovine mammary tissue DNA synthesis and milk production in vitro. J. Dairy Sci., 69 (suppl. 1), 120 (Abstr.).

BAUMRUCKER C. R., 1986b. Insulin-like growth factor 1 (IGF-1) and insulin stimulates DNA synthesis in bovine mammary tissue explants obtained from pregnant cows. J. Dairy Sci, 69 (suppl. 1), 120 (Abstr.).

BAXTER R. C., BRYON J. M., TURTLE J. R., 1980. Somatogenic receptors of rat liver : regulation by insulin. Endocrinology, 107, 1176-1181.

BINES J. A., HART I. C., 1982. Metabolic limits to milk production, especially roles of growth hormone and insulin. J. Dairy Sci, 65, 1375-1389.

BINES J. A., HART I. C., MORANT S. V., 1980. Endocrine control of energy metabolism in the cows : the effect on milk yield and levels of some blood constituents of injecting growth hormone and growth hormone fragments. Brit. J. Nutr., 43, 179-188.

BITMAN J., WOOD D. L., TYRRELL H. F., BAUMAN D. E., PEEL C. J., BROWN A. C. G., REYNOLDS P. J., 1984. Blood and milk lipid responses induced by growth hormone administration in lactating cows. J. Dairy Sci, 67, 2873-2880.

BRUMBY P. J., HANCOCK J., 1955. The galactopoietic role of growth hormone in dairy cattle. N. Z. J. Sci. Technol., 36, 417-436.

BURTON J. H., MCBRIDE B. W., BATEMAN K., MACLEOD G. K., EGGERT R. G., 1987. Recombinant bovine somatotropin: effects on production and reproduction in lactating cows. J. Dairy Sci, 70 (suppl, 1), 175 (Abstr.).

CAMPBELL P. G., BAUMRUCKER C. R., 1986. Characterization of insulin-like growth factor-1/ somatomedin $\mathrm{C}$ receptors in the bovine mammary gland. J. Dairy Sci., 69 (suppl. 1), 163 (Abstr.).

CHALUPA W., BAIRD L., SODERHOLM C., PALMQUIST D. L., HEMKEN R., OTTERBY D., ANNEXSTAD R., VECCHIARELLI B., HARMON R., SINHA A., LINN J., HANSEN W., EHLE F., SCHNEIDER P., EGGERT R., 1987b. Responses of dairy cows to somatotropin. J. Dairy Sci., 70 (suppl. 1), 176 (Abstr.).

CHALUPA W., GALLIGAN G., KRONFELD D. S., 1985. Responses of cows in early lactation to exogenous growth hormone and dietary sodium bicarbonate. J. Dairy Sci, 68 (suppl. 1), 143 (Abstr.).

CHALUPA W., HAUSMAN B., KRONFELD D. S., KENSINGER R. S., MCCARTHY R. D., ROCK D. W., 1984a. Responses of lactating cows to exogenous growth hormone and dietary sodium bicarbonate. I. Production. J. Dairy Sci, 67 (suppl. 1), 107 (Abstr.).

CHALUPA W., HAUSMAN B., KRONFELD D. S., KENSINGER R. S., MCCARTHY R. D., ROCK D. W., 1984b. Responses of lactating cows to exogenous growth hormone and dietary sodium bicarbonate. III. Blood and urine measurements. J. Dairy Sci., 67 (suppl. 1), 108 (Abstr.).

CHALUPA W., MARSH W. E., GALLIGAN D. T., 1987a. Bovine somatotropin : lactational responses and impacts on feeding programs. Proc. Maryland. Nutr. Conf. Feed Manuf., 4857. 
CHALUPA W., VECCHIARELLI B., SCHNEIDER P., EGGERT R. G., 1986. Long-term responses of lactating cows to daily injection of recombinant somatotropin. J. Dairy Sci, 69 (suppl. 1), 151 (Abstr.).

CHILLIARD Y., 1986. Revue bibliographique: Variations quantitatives et métabolisme des lipides dans les tissus adipeux et le foie au cours du cycle gestation-lactation. $1^{\text {re }}$ partie : chez la ratte. Reprod. Nutr. Dévelop., 26, 1057-1103.

CHILLIARD Y., 1987. Revue bibliographique: Variations quantitatives et métabolisme des lipides dans les tissus adipeux et le foie au cours du cycle gestation-lactation. $2^{2}$ partie : chez la brebis et la vache. Reprod. Nutr. Dévelop., 27, 327-398.

CHILLIARD Y., DELOUIS C., SMITH M. C., SAUVANT D., MORAND-FEHR P., 1986. Mammary metabolism in the goat during normal or hormonally-induced lactation. Reprod. Nutr. Dévelop., 26, 607-615.

CHILLIARD Y., SAUVANT D., MORAND-FEHR P., DELOUIS C., 1987. Relations entre le bilan énergétique et l'activité métabolique du tissu adipeux de la chèvre au cours de la première moitié de la lactation. Reprod. Nutr. Dévelop., 27, 307-308.

COXAM V., DAVICCO M. J., OPMEER F., BECKERS J. F., DURAND D., BAUCHARD D., BARLET J. P., 1987. Endocrine regulation of hepatic somatomedin C (IGF-1) production in young calves. In Fetal and neonatal physiology (C. T. JONES, Ed.), Perinatology Press, New York (in press).

DAVIS S. R., COLLIER R. J., 1985. Mammary blood flow and regulation of substrate supply for milk synthesis. J. Dairy Sci, 68, 1041-1058.

DAVIS S. R., GLUCKMAN P. D., HART I. C., HENDERSON H. V., 1987. Effects of injecting growth hormone or thyroxine on milk production and blood plasma concentrations of insulinlike growth factors $I$ and $I I$ in dairy cows. J. Endocr., 114, 17-24.

DEHOFF M. H., ELGIN R. G., COLLIER R. J., CLEMMONS D. R., 1986. Insulin-like growth factor receptor subtypes are regulated during bovine lactation. $68^{\text {th }}$ Annu. Meet. Endocr. Soc., 562 (Abstr.).

DISENHAUS C., BELAIR L., DJIANE J., 1988. Caractérisation et évolution physiologique des récepteurs pour les insulin-like growth factors I et II (IGFs) dans la glande mammaire de brebis. Reprod. Nutr. Dévelop., 28, 241-252.

DePETERS E. J., SMITH N. E., ACEDO-RICO J., 1985. Three or two times daily milking of older cows and first lactation cows for entire lactations. J. Dainy Sci, 68, 123-132.

EISEMANN J. H., HAMMOND A. C., BAUMAN D. E., REYNOLDS P. J., MCCUTCHEON S. N., TYRRELL H. F., HAALAND G. L., 1986b. Effect of bovine growth hormone administration on metabolism of growing hereford heifers : protein and lipid metabolism and plasma concentrations of metabolites and hormones. J. Nutr., 116, 2504-2515.

EISEMANN J. H., TYRRELL H. F., HAMMOND A. C., REYNOLDS P. J., BAUMAN D. E., HAALAND G. L., MCMURTRY J. P., VARGA G. A., 1986a. Effect of bovine growth hormone administration on metabolism of growing hereford heifers : dietary digestibility, energy and nitrogen balance. J. Nutr., 116, 157-163.

ELVINGER F., HEAD H. H., WILCOX C. J., NATZKE R. P., 1987. Effects of administration of bovine somatotropin on iactation milk yield and composition. J. Dairy Sci., 70 (suppl. 1), 121 (Abstr.).

EPPARD P. J., BAUMAN D. E., BITMAN J., WOOD D. L., AKERS R. M., HOUSE W. A., 1985b. Effect of dose of bovine growth hormone on milk composition : alpha-lactalbumin, fatty acids, and mineral elements. J. Dairy Sci., 68, 3047-3054.

EPPARD P. J., BAUMAN D. E., CURTIS C. R., ERB H. N., LANZA G. M., Degeeter M. J., 1987. Effect of 188-day treatment with somatotropin on health and reproductive performance of lactating dairy cows. J. Dairy Sci, 70, 582-591.

EPPARD P. J., BAUMAN D. E., MCCUTCHEON S. N., 1985a. Effect of dose of bovine growth hormone on lactation of dairy cows. J. Dairy Sci, 68, 1109-1115.

ETHERTON T. D., KENSINGER R. S., 1984. Endocrine regulation of fetal and postnatal meat animal growth. J. anim. Sci, 59, 511-528.

FALCONER J., FORBES J. M., BINES J. A., ROY J. H. B., HART I. C., 1980 . Somatomedinlike activity in cattle : the effect of breed, lactation and time of day. J. Endocr., 86, 183-188.

FEKRY A. E., KEYS J. E., CAPUCO A. V., BITMAN J., WOOD D. L., MILLER R. H., 1986. 
Influence of bovine growth hormone on secretion of triglycerides and free fatty acids by mammary, liver and/or adipose tissues explants. J. Dairy Sci., 69 (suppl. 1), 165 (Abstr.).

FLUX D. S., MCKENZIE D. D. S., WILSON G. F., 1984. Plasma metabolite and hormone concentrations in Friesian cows of differing genetic merit measured at two feeding levels. Anim. Prod., 38, 377-384.

FORSYTH I. A., 1983. The endocrinology of lactation. In Biochemistry of lactation, 309-349 (T. B. MEPHAM, Ed.) Elsevier Science Publishers B.V.

FRENCH N. J., DE BOER G., KENNELLY J. J., 1986. Effect of feeding frequency and growth hormone injection on milk production in dairy cows. J. Dairy Sci., 69 (suppl. 1), 153 (Abstr.).

FRONK T. J., PEEL C. J., BAUMAN D. E., GOREWIT R. C., 1983. Comparison of different patterns of exogenous growth hormone administration on milk production in Holstein cows. J. anim. Sci., 57, 699-705.

GERTLER A., ASHKENAZI A., MADAR Z., 1984. Binding sites of human growth hormone and ovine and bovine prolactins in the mammary gland and the liver of lactating dairy cow. Mol. cell. Endocrinol., 34, 51-57.

GERTLER A., COHEN N., MAOZ A., 1983. Human growth hormone but not ovine or bovine growth hormones exhibits galactopoietic prolactin-like activity in organ culture from bovine lactating mammary gland. Mol. cell. Endocrinol., 33, 169-182.

GLUCKMAN P. D., BREIER B. H., DAVIS S. R., 1987. Physiology of the somatotropic axis with particular reference to the ruminant. J. Dairy Sci., 70, 442-466.

GOODMAN H. M., SCHWARTZ J., 1974. Growth hormone and lipid metabolism. Handbook of Physiology, Endocrinology, Vol. IV (2), 211-231. Am. Physiol. Soc. (Washington, DC).

HART I. C., 1983. Endocrine control of nutrient partition in lactating ruminants. Proc. Nutr. Soc., 42, 181-194.

HART I. C., CHADWICK P. M. E., BOONE T. C., LANGLEY K. E., RUDMAN C., SOUZA L. M., 1984. A comparison of the growth-promoting, lipolytic, diabetogenic and immunological properties of pituitary and recombinant-DNA-derived bovine growth hormone (somatotropin). Biochem. J., 224, 93-100.

HART I. C., JOHNSSON I. D., 1986. Growth hormone and growth in meat producing animals. In Control and manipulation of animal growth, 135-159 (BUTTERY P. J., HAYNES N. B., LINDSAY D. B., Eds). Butterworths, London.

HUBER J. T., 1987. The production response of BST : feed additives, heat stress and injection intervals. In National invitational workshop on bovine somatotropin (St Louis, USA), 57-60.

HUTCHISON C. F., TOMLINSON J. E., McGEE W. H., 1986. The effects of exogenous recombinant or pituitary extracted bovine growth hormone on performance of dairy cows. J. Dairy Sci, 69 (suppl. 1), 152 (Abstr.).

JOHNSSON I. D., HART I. C., 1986. Manipulation of milk yield with growth hormone. Recent. Adv. anim. Nutr., 105-123, Butterworths, London.

JOHNSSON I. D., HART I. C., TURVEY A., 1986. Pre-pubertal mammogenesis in the sheep. 3. The effects of restricted feeding or daily administration of bovine growth hormone and bromocriptine on mammary growth and morphology. Anim. Prod., 42, 53-63.

KAZMER G. W., OYLER R., 1987. Plasma growth hormone and insulin concentrations in, and free fatty acid release from adipose tissue cultured in vitro from Holstein cows of differing genetic value during early and late lactation. J. Dairy Sci., 70 (suppl. 1), 120 (Abstr.).

KEYS J. E., CAPUCO A. V., 1985. Effect of bovine growth hormone (bGH) on acetate incorporation by mammary and adipose tissue from Holsteins at different stages of first term gestation and lactation. J. Dairy Sci., 68 (suppl. 1), 106 (Abstr.).

KEYS J. E., CAPUCO A. V., DJIANE J., AKERS R. M., 1986. Numbers and affinities (Ka) of bovine growth hormone and prolactin receptors in livers of beef and dairy cattle in gestation and lactation. J. Dairy Sci., 69 (suppl. 1), 203 (Abstr.).

KEYS J. E., DJIANE J., 1987. Prolactin and growth hormone binding in mammary and liver tissue of lactating cows. J. Recept. Res. (soumis pour publication).

KIK N., COOK R. M., 1986. Effects of bovine somatotropin and IsoPlus on milk production. J. Dairy Sci, 69 (suppl. 1), 158 (Abstr.).

LAND R. B., CARR W. R., HART I. C., OSMOND T. J., THOMPSON R., TILIKARATNE N., 1983. Physiological attributes as possible selection criteria for milk production. 3. Plasma hormone 
concentrations and metabolite and hormonal responses to changes in energy equilibrium. Anim. Prod., 37, 165-178.

LEITCH H. W., BURNSIDE E. B., MacLEOD G. K., McBRIDE B. W., KENNEDY B. W., WILTON J. W., BURTON J. H., 1987. Genetic and phenotypic effects of administration of recombinant bovine somatotrophin to holstein cows. J. Dairy Sci, 70 (suppl. 1), 128 (Abstr.).

LOUGH D. S., MULLER L. D., GRIEL L. C., KENSINGER R. S., AZZARA C. D., DIMICK P. S., 1986. Effects of exogenous bovine growth hormone (bGH) on milk production, milk composition, and mammary lipid metabolism in lactating dairy cows. J. Dairy Sci., 69 (suppl. 1), 153 (Abstr.).

LOUGH D. S., MULLER L. D., KENSINGER R. S., SWEENEY T. F., GRIEL L. C., ETHERTON T. D., 1984. Effect of added dietary fat and exogenous growth hormone on the performance of early lactation Holstein cows. J. Dairy Sci, 67 (suppl. 1), 115 (Abstr.).

LUKES A. J., BARNES M. A., PEARSON R. E., 1987. GH and PRL responses to sire selection and GHRF challenge. J. Dairy Sci., 70 (suppl. 1), 119 (Abstr.).

MACHLIN L. J., 1973. Effect of growth hormone on milk production and feed utilization in dairy cows. J. Dairy Sci, 63, 575-580.

MADON R. J., ENSOR D. M., KNIGHT C. H., FLINT D. J., 1986. Effects of an antiserum to rat growth hormone on lactation in the rat. J. Endocr., 111, 117-123.

MAES M., KETELSLEGERS J. M., UNDERWOOD L. E., 1986. Low circulating somatomedin-C/ insulin-like growth factor $\mathrm{I}$ in insulin-dependent diabetes and malnutrition : growth hormone receptor and post-receptor defects. Acta. endocr., 113 (suppl.), 86-92.

MARINEZ D. I., RICKS C. A., COOK R. M., 1976. Utilization of volatile fatty acids in ruminants. 8. Acetate activation in mammary tissue. J. agric. Food Chem., 24, 927-935.

MARSH W. E., GALLIGAN D. T., CHALUPA W., 1987. Making economic sense of bovine somatotropin use in individual dairy herds. In Nutrient partitioning, Am. Cyanamid Techn. Symp., (California, USA), 59-79.

MIX L. S., 1987. Potential impact of the growth hormone and other technology on the United States dairy industry by the year 2000. J. Dairy Sci., 70, 487-497.

MOHAMMED M. E., JOHNSON H. D., 1985. Effect of growth hormone on milk yields and related physiological functions of Holstein cows exposed to heat stress. J. Dairy Sci., 68, 1123-1133.

MOLLETT T. A., DegeETER M. J., BELYEA R. L., YOUNGQUIST R. A., LANZA G. M., 1986. Biosynthetic or pituitary extracted bovine growth hormone induced galactopoiesis in dairy cows. J. Dairy Sci., 69 (suppl. 1), 118 (Abstr.).

MCBRIDE B. W., BURTON J. H., MACLEOD G. K., 1987. Skeletal muscle energy expenditures associated with $\mathrm{Na}^{+}, \mathrm{K}^{+}$- transport and protein synthesis in somatotropin-treated lactating cows. J. Dairy Sci, 70 (suppl. 1), 175 (Abstr.).

MCCUTCHEON S. N., BAUMAN D. E., 1986a. Effect of pattern of administration of bovine growth hormone on lactational performance of dairy cows. J. Dairy Sci., 69, 38-43.

McCUTCHEON S. N., BAUMAN D. E., 1986b. Effect of chronic growth hormone treatment on responses to epinephrine and thyrotropin-releasing hormone in lactating cows. J. Dairy Sci. 69, 44-51.

MCDOWELL G. H., HART I. C., 1984. Responses to infusion of growth hormone into the mammary arteries of lactating sheep. Can. J. anim. Sci, 64 (suppl. 1), 306-307.

McDOWELL G. H., HART I. C., BINES J. A., LINDSAY D. B., 1983. Effects of exogenous growth hormone in lactating cows. Proc. Nutr. Soc. Aust., 8, 165 (Abstr.).

McDOWELL G. H., LEENANURUKSA D., GOODEN J. M., JOIS M., ANNISON E. F., 1984. Effects of growth hormone on muscle and mammary metabolism in cows. Proc. Nutr. Soc. Aust., 9, 164 (Abstr.).

McGUfFEY R. K., GREEN H. B., BASSON R. P., 1987b. Performance of Holsteins given bovine somatotropin in a sustained delivery vehicle. Effect of dose and frequency of administration. J. Dairy Sci., 70 (suppl. 1), 177 (Abstr.).

McGUFFEY R. K., GREEN H. B., FERGUSON T. H., 1987a. Lactation performance of dairy cows receiving recombinant bovine somatotropin by daily injection or in a sustained release vehicle. J. Dairy Sci., 70 (suppl. 1), 176 (Abstr.).

PEEL C. J., BAUMAN D. E., 1987. Somatotropin and lactation. J. Dairy Sci, 70, 474-486. 
PEEL C. J., BAUMAN D. E., GOREWIT R. C., SNIFFEN C. J., 1981. Effect of exogenous growth hormone on lactational performance in high yielding dairy cows. J. Nutr., 111, 1662-1671.

PEEL C. J., FRONK T. J., BAUMAN D. E., GOREWIT R. C., 1982. Lactational response to exogenous growth hormone and abomasal infusion of a glucose-sodium caseinate mixture in high yielding dairy cows. J. Nutr., 112, 1770-1778.

PEEL C. J., FRONK T. J., BAUMAN D. E., GOREWIT R. C., 1983. Effect of exogenous growth hormone in early and late lactation on lactional performance of dairy cows. J. Dairy Sci., 66. 776-782.

PEEL C. J., SANDLES L. D., QUELCH K. J., HERINGTON A. C., 1985. The effects of longterm administration of bovine growth hormone on the lactational performance of identicaltwin dairy cows. Anim. Prod., 41, 135-142.

PERIER A., KANN G., MARTINET J., 1987. Effects of somatocrinine (GRF) on hormonal plasma levels, liver $\mathrm{GH}$ binding and mammary growth in induced lactation ewes. Comm. Journée d'Automne d'information scientifique du centre de recherches de Jouy-en-Josas (I.N.R.A.), 16-17.

POCIUS P. A., HERBEIN J. H., 1986. Effects of in vitro administration of growth hormone on milk production and in vitro hepatic metabolism in dairy cattle. J. Dairy Sci., 69, 713-720.

RÉMOND B., 1985. Influence de l'alimentation sur la composition du lait de vache. 2 . Taux protéique : facteurs généraux. Bull. Tech. CRZV Theix, I.N.R.A., 62, 53-67.

RÉMOND B., CHILLIARD Y., CISSE M., 1987. Effets d'injections bimensuelles de somatotropine sur l'ingestion, les performances et le métabolisme de vaches laitières recevant deux niveaux d'aliments concentrés (Résultats préliminaires).

RICHARD A. L., McCUTCHEON S. N., BAUMAN D. E., 1985. Responses of dairy cows to exogenous bovine growth hormone administered during early lactation. J. Dairy Sci, 68 , 2385-2389.

SCHNEIDER P. L., VECCHIARELLJ B., CHALUPA W., 1987. Bovine somatotropin and ruminally inert fat in early lactation. J. Dairy Sci., 70 (suppl. 1), 177 (Abstr.).

SCHOCKMEL L., 1986. Contribution à l'étude des effets de la somatotropine bovine methionylée chez des vaches laitières à haute production. Thèse Doct. Vétérinaire, Univ. Toulouse.

SEJRSEN K., FOLDAGER J., SORENSEN M. T., AKERS R. M., BAUMAN D. E., 1986. Effect of exogenous bovine somatotropin on pubertal mammary development in heifers. J. Dairy Sci., 69, 1528-1535.

SIMKINS K. L., 1987. Development of bovine somatotropin for dairy cattle. In Nutrient partitioning. Am. Cyanamid Techn. Symp. (California, USA), 36-45.

SODERHOLM C. G., OTTERBY D. E., EHLE F. R., LINN J. G., HANSEN W. P., ANNEXSTAD R. J., 1986b. Effects of different doses of recombinant bovine somatotropin (rbSTH) on milk production, body composition, and condition score in lactating cows. J. Dairy Sci., 69 (suppl. 1), 152 (Abstr.).

SODERHOLM C. G., OTTERBY D. E., LINN J. G., WHEATON J. E., HANSEN W. P., ANNEXSTAD R., 1986a. Effects of different doses of recombinant bovine somatotropin (rbSTH) on circulating metabolites, hormones, and physiological parameters in lactating cows. J. Dairy Sci., 69 (suppi. 1), 152 (Abstr.).

SPENCER G. S. G., 1985. Hormonal systems regulating growth. A review. Livestock Prod. Sci., 12, 31-46.

THOMAS C., JOHNSSON I. D., FISHER W. J., BLOOMFIELD G. A., MORANT S. V., WILKINSON J. M., 1987. Effect of somatotrophin on milk production, reproduction and health of dairy cows. J. Dairy Sci, 70 (suppl. 1), 175 (Abstr.).

TRUSCOTT T. G., WOOD J. D., GREGORY N. G., HART I. C., 1983. Fat deposition in Hereford and Friesian steers. 3. Growth efficiency and fat mobilization. J. agric. Sci., Camb., 100, $277-$ 284.

TYRRELL H. F., BROWN A. C., REYNOLDS P. J., HAALAND G. L., PEEL C. J., BAUMAN D. E., STEINHOUR W. C., 1982. Effect of growth hormone on utilization of energy by lactating Holstein cows. In EKERN A., SUNDSTOL F., Energy metabolism of farm animals. EAAP. Publ. No 29, 46-47.

VÉRITÉ R., JOURNET M., 1978. Vaches laitières, 345-376. In Alimentation des Ruminants, I.N.R.A. Publ., 78000 Versailles. 
VERNON R. G., 1982. Effects of growth hormone on fatty acid synthesis in sheep adipose tissue. Int. J. Biochem., 14, 255-258.

VERNON R. G., 1986. The response of tissues to hormones and the partition of nutrients during lactation. Hannah Res. Inst., Rep. 1985, 115-121.

WALTON P. E., ETHERTON T. D., 1986. Stimulation of lipogenesis by insulin in swine adipose tissue : antagonism by porcine growth hormone. J. anim. Sci, 62, 1584-1595. 